\title{
Land cover analysis as a tool for water resources quality assessment - example study from selected river basins of Slovakia.
}

\author{
Cyril SIMAN - Yvetta VELÍSKOVÁ \\ Institute of Hydrology Slovak Academy of Sciences, Dubravska cesta 9, 84104 Bratislava, Slovakia; E-mail: \\ siman@uh.savba.sk, veliskova@uh.savba.sk
}

Keywords: water quality, land cover analysis, surface streams, river basin, Slovakia

\section{Introduction}

Water quality is affected by a combination of natural and anthropogenic factors, the relative influences of which change with temporal and spatial scale (Mouri et al., 2011). Majority of these factors can be and have been, strongly affected by humans. For example, changes in river discharge due to abstraction, urbanization, and discharges from industry, agriculture or sewerage. The pollution problem is caused by changes in the composition of land use within a catchment as human activities increase (Boskidis et al., 2011)-

\section{Materials and methods}

This study includes an analysis of the land cover categories with prevailing size in the river catchment. We assume that in a catchment in which forests and semi-natural areas prevail ("forest river basins"), the concentration of the pollution of surface streams will be lower than in catchments with prevailing areas of agricultural land ("farm or agricultural river basins"). Data about concentrations of pollutants for the period 2006 - 2017 (12-year period) was provided by Slovak Hydrometeorological Institute. Data about land cover (Corine land cover 2012) we obtained from Copernicus programme. Categories of land cover we divided into two main groups: 1) forest and semi-natural areas, 2) agricultural areas. Concentrations of pollutants are represented by the median value of processed time series.

We compared the average values of the concentration of pollution for each water quality indicator in three catchments with a predominance of forest and semi-natural land cover categories as well as three catchments with predominantly agricultural areas.

\section{Conclusions}

We determined that in so-called forest catchments, the concentrations of pollutants in each of the water quality indicators were lower in comparison with the agricultural river basins. The differences of particular water quality indicators values had not the same range. The highest differences between forest and agricultural areas were in the biochemical oxygen demand and suspended solids. On the other hand, the total phosphorus and phosphate water quality indicators showed very small differences. Our results show that an analysis of land cover is not sufficient to estimate the water quality of surface streams in river basins unequivocally, however it can be used for a first assessment of the potential load of surface streams by pollution. 


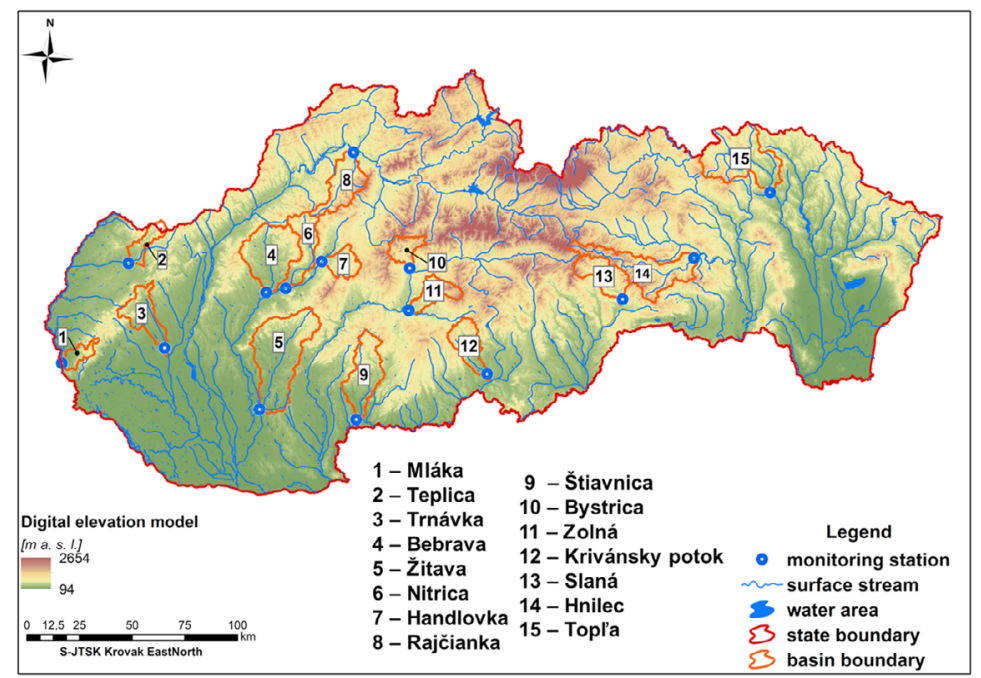

Figure 1: Analysed river basins

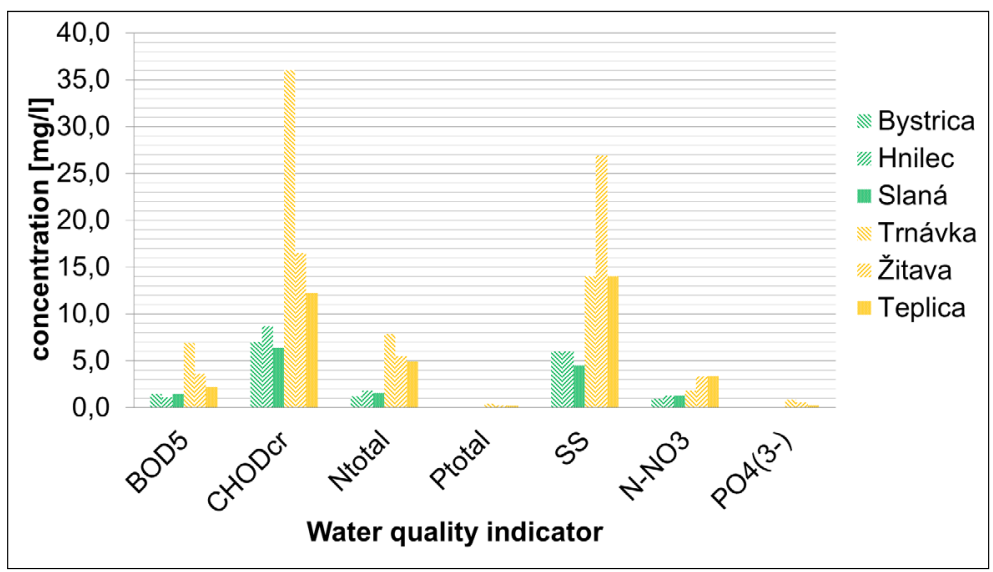

Figure 2: Individual water quality indicator values in selected river basins.

\section{Acknowledgement}

The study was created with support from VEGA project no. 1/0805/16. This contribution/ publication is the result of the project implementation ITMS 262401200004 Centre of excellence for the Integrated River Basin Management in the Changing Environmental Conditions, supported by the Research \& Development Operational Programme funded by the ERDF.

\section{References}

Boskidis, I., Gikas, G, D., Pisinaras, V., Tsihrintzis, V., A. (2011): Spatial and temporal changes of water quality, and SWAT modeling of Vosvozis River Basin, North Greece. J Environ Sci Health A 45(15):421-1440. https:// doi.org/10.1080/10934529.2010.500936

Mouri, G., Takizawa, S., Oki, T. (2011): Spatial and temporal variation in nutrient parameters in stream water in a rural-urban catchment, Shikoku, Japan: Effects of land cover and human impact. Journal of Environmental Management 92, 2011, 1837-1848. https://doi.org/10.1016/j.jenvman.2011.03.005 